\title{
Identification of antagonistic Streptomyces strains isolated from Algerian Saharan soils and their plant growth promoting properties
}

\author{
LAMIA AOUAR ${ }^{1,2, \boldsymbol{v}}$, INAS BOUKELLOUL ${ }^{3}$, ABDERRAHMANE BENADJILA ${ }^{3}$ \\ ${ }^{1}$ Laboratory of Active Components and Materials, Larbi Ben M'Hidi University. PO Box 358, Oum El Bouaghi, 04000, Algeria \\ ${ }^{2}$ Department of Biological Engineering, Institute of Technology, Larbi Ben M'Hidi University. PO Box 358, Oum El Bouaghi, 04000, Algeria, \\ Tel.: +21-3560703268, `email: aouarlamia@yahoo.fr \\ ${ }^{3}$ Department of Natural Sciences and Live, Larbi Ben M'Hidi University. PO Box 358, Oum El Bouaghi, 04000, Algeria
}

Manuscript received: 17 October 2020. Revision accepted: 13 November 2020.

\begin{abstract}
Aouar L, Boukelloul I, Benadjila A. 2020. Identification of antagonistic Streptomyces strains isolated from Algerian Saharan soils and their plant growth promoting properties. Biodiversitas 21: 5672-5683. To produce new bioactive substances of agricultural interest, extreme ecosystems can be a source of unexplored microorganisms. Accordingly, in this study, twenty-two actinobacteria strains were obtained from rhizospheric arid soils of palm groves collected from Biskra and El Oued in the Algerian Sahara. All isolates were examined for the in vitro antifungal potential towards phytopathogenic fungi: Aspergillus flavus, Verticillium dahlia, Rhizoctonia solani, Botrytis cinerea and Fusarium oxysporum as well as for their antibacterial property toward phytopathogenic bacteria: Streptomyces scabiei, Pectobacterium carotovorum and Agrobacterium tumefaciens. The three isolates (13\%) that inhibited at least five pathogens were then selected, identified and assessed for their attributes to produce indole-3-acetic acid (IAA) and siderophores, to solubilize phosphate, and to antagonize Streptomyces scabiei in vivo. According to phylogenetic analysis performed with 16S rDNA sequence, chemotaxonomy and phenotypic characteristics, the strain SO1, which inhibited all tested pathogens, was assigned to Streptomyces flaveus. While, strains SO2 and SB1 were affiliated to Streptomyces enissocaesilis and Streptomyces albidoflavus, respectively. All strains produced IAA but only SO1 and SB1 were able to elaborate siderophores catecholate-type. Two strains SO1 and SO2 exhibited a capacity to solubilize phosphate and SO1 was able to suppress the pathogenic effect of Streptomyces scabiei on radish seedlings. The findings indicate that SO1 strain may reveal the potential for use as a biocontrol agent and plant grow th promoter.
\end{abstract}

Keywords: Antagonism, arid soil, indol-3-acetic acid, phosphate, siderophores, Streptomyces

\section{INTRODUCTION}

The emergence of resistance in fungal plant pathogen strains poses serious public health and environmental menace all over the world (Sharma and Manhas 2020). Currently, crop-destroying fungi cause yield losses of about $20 \%$ worldwide, with an additional $10 \%$ loss postharvest (Fisher et al. 2018). In addition to fungal diseases, there are those engendered by bacteria, such as common scab, which is characterized by dark lesions that develop especially on tubers, and the main causal agent is Streptomyces scabiei (Khalil et al. 2019). Hence, the utilization of beneficial microorganisms as biological control agents is considered an environmental friendly alternative to combat crop diseases and pesticide resistance. Among microorganisms, actinobacteria especially Streptomyces are recognized for their ability to generate various active compounds with agricultural applications (Liu et al. 2019).

Actinobacteria are Gram-positive bacteria that occur naturally in soils. Recently, they have attracted great interest because these bacteria can be applied in agriculture and also in the industry for the synthesis of bioactive metabolites and other natural bioactive compounds. In the rhizospheric soil, actinobacteria constitute a major part of the bacterial community and can exercise an antagonistic and competitive action on the microbial populations. Members of this group produce active compounds such as antibacterial and antifungal antibiotics, plant growth regulators, and siderophores (Khamna et al. 2010).

To promote plant growth, actinobacteria possess multifunctional plant growth-promoting (PGP) attributes and enhance plant growth directly by the production of phytohormones such as indole-3-acetic acid (IAA), solubilization of minerals like phosphate, and siderophores secretion. The latest are low molecular weight compounds, they sequester iron from the soil and deliver it to the plant. Bacteria generally synthesize two types of siderophores: the catechol type and the hydroxamate type. IAA is an indole derivative that has several functions to enhance plant growth, such as root formation, stimulation of cell division, extension, and differentiation (Hider and Kong 2010; Yadav et al. 2018).

The majority of rhizospheric actinobacteria are Streptomyces (66\%) (Apsari et al. 2019). They are characterized by their complex life cycle and high GC content (more than 70\%) (Lee et al. 2020). Streptomyces sp. is the most important producer of secondary metabolites (39\% of the total metabolites produced by microorganisms) (Subramaniam et al. 2020). Moreover, 60\% of antibiotics, insecticides, and herbicides developed for agriculture use are isolated from Streptomyces (Suwan et al. 2012; Vurukonda et al. 2018). Unfortunately, many previous screening studies for new compounds have focused on new actinobacteria from the usual natural environment, 
resulting in a re-isolation of already existing bioactive compounds. Thus, research has been oriented towards new, extreme, or under-explored habitats in the hope of discovering promising new species capable of producing new bioactive compounds (Mohamed et al. 2017).

Algerian Sahara is characterized by a hot arid climate and presents a particular ecosystem. Recently, there has been a new interest in the resources of actinobacteria from Algerian arid zones, considering that high temperatures can induce metabolic adaptations which could result in the production of interesting metabolites (Djinni et al. 2019). Effectively, many studies have contributed to the finding of new species of actinobacteria in poorly explored arid environments, notably through the isolation of rare genera: Mzabimyces algeriensis (Saker et al. 2014), Actinopolyspora algeriensis (Meklat et al. 2012), Planomonospora algeriensis (Chaabane-Chaouch et al. 2017). As a result, from 2002 to 2019, one new genus and twenty-nine new species were obtained, mainly from palm groves and Algerian Saharan soils. Several of these strains were proved capable of producing antibacterial and antifungal metabolites, including 17 new molecules among the 50 structures reported (Djinni et al. 2019; Lahoum et al. 2019). Actinobacteria isolated from arid and other extreme ecosystems remain the inexhaustible source of new antimicrobials, offering an opportunity to get new bioactive metabolites (Djinni et al. 2019).

The objective of the current study is to isolate rhizospheric actinobacteria from Algerian arid soils and to screen isolates exhibiting antagonistic activity against plant pathogens, fungi, and bacteria. The selected isolates are subjected to polyphasic identification: chemotaxonomic, morphological, physiological, and biochemical characteristics, as well as $16 \mathrm{~S}$ rRNA gene sequencing. Selected isolates are also screened for their aptitude to solubilize inorganic phosphate, to produce IAA and siderophores, and to antagonize $S$. scabiei in vivo.

\section{MATERIALS AND METHODS}

\section{Isolation and screening of antagonistic activity}

The Saharan soils were sampled in January 2016, from the rhizosphere of two palm groves, the first is located on the site $\left(33^{\circ} 09^{\prime} 36^{\prime \prime} \mathrm{N}, 6^{\circ} 34^{\prime} 09^{\prime \prime} \mathrm{E}\right)$ in Draa LahmarMihouansa, Province of El Oued, and the second is located on the site $\left(34^{\circ} 42^{\prime} 52^{\prime \prime} \mathrm{N}, 5^{\circ} 22^{\prime} 16^{\prime \prime} \mathrm{E}\right)$ in M'toura-Tolga, Province of Biskra. Based on Köpper climate classification both M'toura-Tolga and Draa Lahmar-Mihouansa are characterized by BWh (hot desert climate). But according to Emberger's rainfall quotient, which specifies the bioclimatic stages, Draa Lahmar-Mihouansa region is characterized by the Saharan climate $\left(\mathrm{Q}_{2}=6.75\right)$, while M'toura-Tolga region is characterized by the arid climate $\left(\mathrm{Q}_{2}=13.33\right)$. Decimal dilutions (from $10^{-1}$ to $\left.10^{-7}\right)$ were spread on isolation medium ISP2 (International Streptomyces Project-2) amended by cycloheximide (100 $\mu \mathrm{g} \mathrm{mL}{ }^{-1}$ ), then incubated for 21 days at $28^{\circ} \mathrm{C}$ (Khamna et al. 2010). Typical actinobacteria colonies were picked, purified, and maintained in glycerol $(20 \% \mathrm{v} / \mathrm{v})$ (Ser et al. 2018; Abbasi et al. 2019).
Antibacterial activity was determined against three phytopathogenic bacteria: P. carotovorum, A. tumefaciens, and S. scabiei using the agar cylinder technique (Rizvi et al. 2014). The inhibition zones were measured within $24 \mathrm{~h}$. The screening of isolates exhibiting antifungal activity was carried out using methanol extracts obtained from cultures on solid medium (glycerol yeast extract peptone agar), according to a modified procedure of Lee et al. (1995). Antifungal property is evaluated by testing the methanolic culture extracts of the isolates against 5 phytopathogenic fungi, which are isolated and identified locally: $B$. cinerea SOL-1, F. oxysporum CIT-4, V. dahlia OLE-2, R. solani SOL-5, and A. flavus TRI-4. The disc of the fungal culture (8 $\mathrm{mm}$ ) was deposited in the middle of the Petri dish containing PDA amended with the methanolic extract. The fungal growth was recorded when control colonies reach 8 $\mathrm{cm}$. The percentage of inhibition was calculated as follows:

$$
\begin{aligned}
& \% \text { inhibition of } \\
& \text { mycelial growth }
\end{aligned}=1-\frac{\begin{array}{c}
\text { Diameter of mycelial growth with } \\
\text { methanolic extract (treated plate) }
\end{array}}{\begin{array}{c}
\text { Diameter of mycelial growth } \\
\text { on untreated plates }
\end{array}} \times 100
$$

\section{Phenotypic and chemotaxonomic characteristics}

Morphological traits and melanoïd pigments were examined on ISP media (ISP2, ISP3, ISP4, ISP5, ISP6, and ISP7) as recommended by Shirlling and Gottlieb (1966). Plates were incubated at $28{ }^{\circ} \mathrm{C}$ for 14 days, and then the colony color was determined using CCIS-NBS color maps. The cover-slip technique was performed in order to determine spore chain arrangement as described by Williams et al (1983). Cover-slips were examined after 14 days of incubation on ISP4 medium at $28{ }^{\circ} \mathrm{C}$. To observe spore-surface ornamentation, cultures were fixed with $1 \%$ (w/v) osmium tetroxide then coated with platinum in a sputter coater and observed under scanning electron (Aouar et al. 2012). The isolates were evaluated for 50 biochemical and physiological characteristics (Table 1). The ability to assimilate different sources of carbon was performed on the basic medium ISP 9 (Shirlling and Gottlieb, 1966) amended with $1 \%(\mathrm{w} / \mathrm{v})$ for sugars (D-glucose, Larabinose, D-fructose, D-lactose, mannitol, D-maltose, raffinose, sucrose, D-mannose, L-rhamnose, D-xylose, sorbose, Myo-inositol, glycerol, xylitol, adonitol, sorbitol, melezitose, and melibiose) and $0.1 \%(\mathrm{w} / \mathrm{v})$ for organic acids (citrate and propionate). The use of nitrogen sources on Bennett medium (supplemented at $0.1 \%$, w/v) was assessed as described by Williams et al. (1983). For both carbon and nitrogen sources, growth was noted after 14 days by comparing the test plates with the negative and positive control plates. Enzymatic and degradation activities were evaluated according to the procedures of Williams et al. (1983). Growth inhibition assays were conducted on MBA (modified Bennett's agar), which was added by the following inhibitors: phenol $(0.1 \%$, w/v), sodium azide $(0.01 \%, \mathrm{w} / \mathrm{v})$, crystal violet $(0.0001 \%, \mathrm{w} / \mathrm{v})$, thallous acetate $(0.01 \%, \mathrm{w} / \mathrm{v})$ and potassium tellurite $(0.01 \%, \mathrm{w} / \mathrm{v})$. Tolerance sensitivity to lysozyme $(10,50$, and $100 \mu \mathrm{g} \mathrm{mL}^{-1}$ ) was tested as described by Williams et al. 
(1983). $\mathrm{NaCl}$ tolerance was evaluated in tryptic soybean broth (TSB) with concentrations starting from 0 to $13 \%$ $(w / v)$. For all these tests, estimation of growth was noted after 7 and 14 days. Growth at different temperatures was tested within a range of 4 to $45^{\circ} \mathrm{C}$. Tolerance to $\mathrm{pH}$ was tested on tryptic soybean broth medium (TSB) with $\mathrm{pH}$ values ranging from 4 to 10 . Chemical composition of the cell wall and the whole-cell hydrolysate were analyzed according to the procedure of Becker et al. (1964) and Lechevalier and Lechevalier (1980).

\section{Molecular identification and phylogenetic analysis}

Genomic DNA was extracted and purified as described by Franco-Correa et al. (2010). The amplification primers were F27 [5'AGAGTTTGATCCTGGCTCAG3'] and R1492 [5'TACGGCTACCTTGTTACGACTT3'] (Aouar et al. 2012; Sudiana et al. 2020). PCR conditions were $5 \mathrm{~min}$ of predenaturation at $95{ }^{\circ} \mathrm{C}$; and then 35 cycles including $1 \mathrm{~min}$ of denaturation at $95^{\circ} \mathrm{C}, 1 \mathrm{~min}$ of annealing at $50{ }^{\circ} \mathrm{C}$, and 2 min of extension at $72{ }^{\circ} \mathrm{C}$. The PCR amplified samples were immediately sequenced. The obtained sequences were submitted to GenBank under accession numbers KX822695, KX822695, and KX822695 for SO1, SO2, and SB1 isolates, respectively. The rDNA sequences were analyzed by BLAST. The alignment of sequences with their representative related type strains retrieved from the GenBank databases was performed by Clustal W2 software. A phylogenetic tree was built using Mega 6 software (Tamura et al. 2013), according to the NeighborJoining (NJ) method supported by the bootstrap test of 1000 replications and the Kimura two-parameter model. Bacillus subtilis ATCC 6633T was employed as an outgroup (Figure 3). From the extracted genomic DNA, the Mole\% of GC was obtained following a fluorimetric method of DNA amplification using the fluorescent dye specific to double-stranded DNA (SYBRGreen) and the qRT-PCR thermocycler to obtain the dissociation curve. Tm was determined from the minimum value of the slope of the dissociation curve (fluorescence as a function of temperature). Then, the Mole\% of GC was calculated from the Tm according to the equation of Gonzalez and SaizJiménez (2005) GC\%=1,98 Tm - 106,91.

\section{Indol-3-acetic acid production}

The isolates were tested for indol-3-acetic acid (IAA) production using a modified method of Khamna et al. (2009). Starch minimal medium enriched with three concentrations of L-tryptophan $(2.5,5$, and $7.5 \mathrm{mM})$ was used. The IAA was detected in the supernatant with Salkowski's reagent. The development of the pink color after 30 minutes indicated a positive reaction. Ethyl acetate was employed for IAA extraction. Extracts samples were dried and dissolved in acetonitrile before being analyzed by HPLC (Agilent 1260 Series, Agilent Technologies, Santa Clara, CA, USA) using a C18 reverse-phase column (Zorbax SB-C18, Agilent Technologies). The mobile phase was acetonitrile/water/acetic acid 35/65/1 with $1 \mathrm{~mL}$ min $\mu \mathrm{g} \mathrm{mL} \mathrm{m}^{-1}$ as flow rate, and the detection was performed at $280 \mathrm{~nm}$ (Aouar et al. 2016). The amounts of IAA detected were determined from a standard curve constructed with commercial IAA.

\section{Siderophore production}

Siderophore production was detected as stated by Sadeghi et al. (2012) and Gangwar et al. (2014). Discs (6 $\mathrm{mm}$ ) were collected from isolates cultures (SO1, SO2, and SB1), placed on Chrom Azurol S (CAS) plates, and then incubated for 7 days at $30{ }^{\circ} \mathrm{C}$. The development of an orange zone is considered positive for siderophore production. The positive isolates with the CAS test were maintained and examined for the siderophore type tests. The hydroxamate-type of siderophores was detected by the method of (Atkin et al. 1970). Their presence in the supernatant was revealed by the iron perchlorate reagent. Red color development revealed a positive reaction. The catechol-type of siderophores was assessed using Arnow's reagent as described by Lee et al. (2012). Isolates were inoculated in a modified Fiss glucose medium. The supernatant was collected, while the biomass was dried and expressed in $\mathrm{mg}$ on a dry weight basis. Equal volumes (1 $\mathrm{mL})$ of supernatant, $\mathrm{HCl}(0.5 \mathrm{~N})$ and $\mathrm{NO}_{2}$-Mo aqueous solution $\left(10 \% \quad \mathrm{NaNO}_{2}\right.$ and $10 \%$ NaMo, wt/vol) were mixed. Then, $1 \mathrm{~mL}$ of $\mathrm{NaOH}(1 \mathrm{~N})$ was added. The change of color to pink-red signifies a positive reaction. To study the kinetics of catechols production, isolates SO1 and SB1 were grown in Fiss glucose. During incubation, catechols were extracted every $12 \mathrm{~h}$ with ethyl acetate. The obtained extracts were examined by HPLC using C18 reverse-phase column (Zorbax SB-C18, Agilent Technologies) as described for IAA (Aouar et al. 2016).

\section{Phosphate solubilization}

The phosphate solubilization test is performed on Pikovskaya medium containing $5 \mathrm{~g} \mathrm{~L}^{-1}$ of tricalcium phosphate $\left(\mathrm{Ca}_{3}\left(\mathrm{PO}_{4}\right)_{2}\right)$ (TCP) as described by (FrancoCorrea et al. 2010, Mohandas et al. 2013). The formation of a clear area surrounding the colonies reveals phosphate solubilization. Halo diameters are determined by subtracting the colony diameter from the total diameter.

\section{In vivo antagonism against Streptomyces scabiei}

This test was conducted on radish seedlings (Raphanus sativus L. var sativus) in growth bags as previously described by Legault et al. (2011). Three types of tests were performed positive control (inoculated with $S$. scabiei) negative control (no inoculated) and treatments (co-inoculated with S. scabiei and the antagonist isolate). Pouches were incubated for 6 days at $21^{\circ} \mathrm{C}$, then scanned and the obtained pictures were processed by Ez-Rhizo 1.0 software to measure root length.

\section{Statistical analysis}

The tests were performed in quadruplicate and all results were presented as a mean \pm standard deviation (SD). Analysis of the data was performed using an analysis of variance (ANOVA) with the statistical software SPSS Statistics 23.0, consolidated by the least significant difference (LSD) test. The difference was estimated to be statistically significant when $\mathrm{p}<0.05$. 


\section{RESULTS AND DISCUSSION}

\section{Screening of antagonistic isolates}

Twenty-two isolates were obtained from soils sampled from the two rhizospheric sites: Biskra 15 (68\%) and El Oued $7(31 \%)$. All the isolates were maintained and analyzed for antifungal and antibacterial potentialities. Putrie et al. (2020) found that the major microorganisms in the rhizospheric soil are actinobacteria. Also, Khamna et al. (2009) demonstrated that microorganisms from the rhizosphere are most ideal for controlling plant pathogens that's why we have explored rhizospheric soil. According to this study, the soil of Biskra provided the greatest number of isolates compared to that of El Oued. These results are compatible with those of Boudemagh et al. (2005). They reported the abundance of actinobacteria in the soil of Biskra compared to that of El Oued. This is possibly due to the climate, which is more arid in El Oued. Out of the 22 isolates, $12(54 \%)$ presented antagonistic activity towards at least one microorganism-test, 11 (50\%) isolates exhibited antifungal activity and $6(27 \%)$ isolates showed antibacterial antagonism. Our results corroborate with those obtained by Singh et al. (2019), where they found that $23 \%$ of the isolates had antibacterial activity, while $47 \%$ were able to inhibit fungi. However, Boudmagh et al. (2005) reported that, among the 27 isolates of arid soil, only $7 \%$ showed antifungal activity. The highest rate of active isolates was recorded against $V$. dahlia $10(45 \%)$, followed by $A$. flavus and $B$. cinerea $9(40 \%)$ and $F$. oxysporum $7(31 \%)$, while the lowest rate was displayed toward $R$. solani $4(18 \%)$. Further experiments were conducted on isolates that inhibited the growth of at least five pathogens (SO1, SO2, and SB1). Results of antagonistic activities of the selected isolates are presented in Table 1 .

As shown in Table 1, SO1 exhibited antagonistic activity against all pathogens. Isolate $\mathrm{SO} 2$ exhibited the highest activity toward $P$. carotovorum $(26.33 \mathrm{~mm}$ ) (Figure 1). Boudjeko et al. (2017) have also found that $S$. cameroonensis, isolated from the rhizosphere, was able to inhibit in vitro the growth of $S$. scabiei and Agrobacterium tumefaciens. SO2 displayed the highest $V$. dahlia inhibition $(60.0 \%)$ followed by SO1 (51.25\%). However, R. solani was the most resistant. Antagonism of actinobacteria against pathogenic fungi has been assessed for a large variety of fungi. In this view, several researches have been done showing the ability of actinobacteria isolates to antagonize phytopathogenic fungi (Aouar et al. 2012; Goudjal et al 2016; Abbasi et al 2019).

Inhibition rates obtained in our study are not unexpected because, with antagonistic actinobacteria, Goredema et al. (2020) recorded an inhibition rate of 55\% against A. flavus and $F$. oxysporum. Also, Aouar et al. (2012) reported that $54 \%$ of rhizospheric actinobacteria isolates exhibited antagonism against $F$. oxysporum, and $33 \%$ were capable of inhibiting the spread of $V$. dahliae. The proportion of active isolates against $V$. dahlia, recorded in this study, was higher than that obtained by Xue et al. (2013). Also, recent studies (Sharma and Manhas 2020; Sudiana et al. 2020) have found that F. oxysporum was also sensitive to antagonistic actinobacteria isolated from soil.

Table 1. Results of antibacterial and antifungal activities of the selected isolates.

\begin{tabular}{lcccccccc}
\hline & \multicolumn{4}{c}{ Inhibition zones $(\mathbf{m m})$} & \multicolumn{4}{c}{ \% inhibition of mycelial growth } \\
\cline { 2 - 8 } Isolates & \multicolumn{3}{c}{ Phytopathogenic bacteria } & \multicolumn{4}{c}{ Phytopathogenic fungi } \\
\cline { 2 - 9 } & S. scabiei & $\boldsymbol{P .}$ carotovorum & A. tumefaciens & F. oxysporum & B. cinerea & R. solani & V. dahliae & A. flavus \\
\hline SO1 & $23.66 \pm 1.15$ & $14.67 \pm 1.15$ & $17.33 \pm 1.52$ & 25.00 & 30.25 & 12.5 & 51.25 & 37.5 \\
SO2 & n.i. & $26.33 \pm 2.08$ & n.i. & 10.0 & 18.75 & 6.25 & 60.0 & 43.75 \\
SB1 & n.i. & n.i. & n.i. & 22.5 & 28.75 & 13.75 & 41.25 & 35.00 \\
\hline
\end{tabular}

Note: n.i.: no inhibition
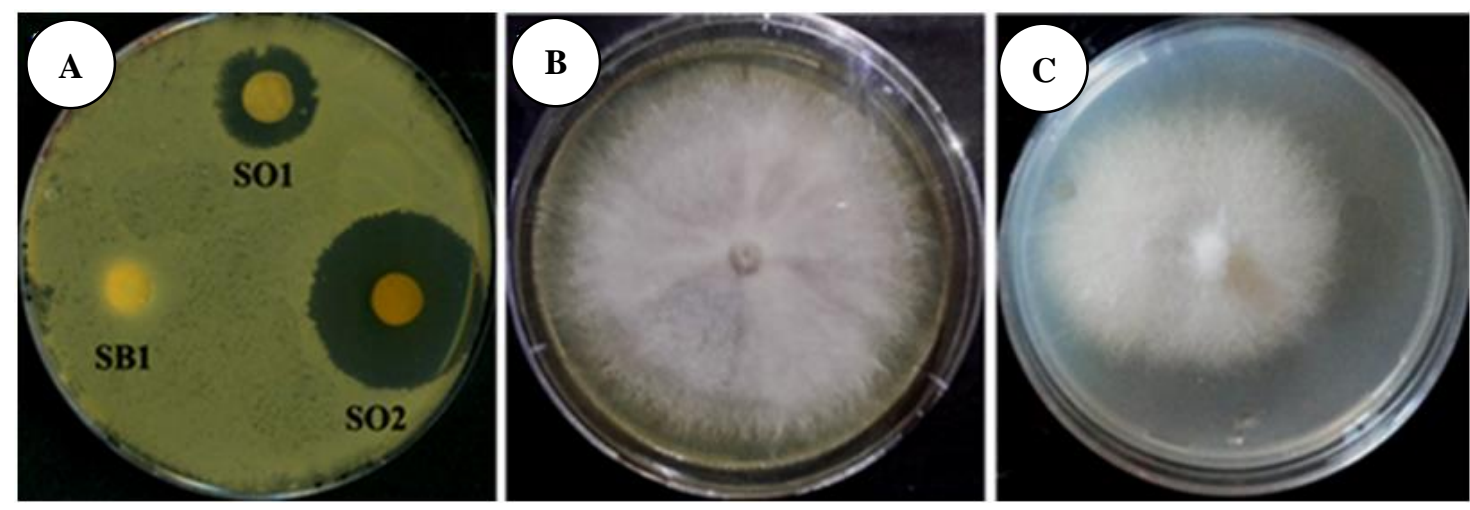

Figure 1.A. Antibacterial activity against Pectobacterium carotovorum; B. Fusarium oxysporum growth on PDA without SO1 extract; C. F. oxysporum growth with $\mathrm{SO} 1$ extract 


\section{Genera associated with the selected isolates}

Morphological and physiological traits are summarized in Table 2. The results show that all strains are fastgrowing. They are differentiated by the color of their spore mass, which is grey, white, and yellow for $\mathrm{SO} 1, \mathrm{SO} 2$, and $\mathrm{SB} 1$, respectively. It has been observed that spore chains forms are rectiflexibiles for SB1, and spiral for both $\mathrm{SO} 2$ and SO1. The scan electron micrographs show the cylindrical form and smooth surface of the spores (Figure 2). For all strains, melanin and colored diffusible pigments are not formed. Selected isolates develop colonies after 48 hours of incubation, which characterizes fast-growing actinobacteria. These rapid-growing strains lack mycolic acids in their walls and can therefore be placed either with Streptomyces and related genera or with Thermomonospora and related genera. For all isolates, the cell wall hydrolysate revealed levo isomer of diaminopimelic acid (LL-DAP) as the major constituent of peptidoglycan in addition to the glycin, and no characteristic sugars (arabinose, xylose, madurose) have been detected in the whole-cell hydrolysate. Based on Williams et al. (1989) recommendations, the detection of LL-DAP isomer, and the absence of characteristic sugars indicates the presence of the parietal chemotype I, typical of Streptomyces and related genera.

Barka et al. (2016) reported that the principal characteristics employed for determining the genus level of actinobacteria are macroscopic and microscopic morphology in conjunction with chemotaxonomy. For example, substrate mycelium bearing spores, or formation of sporangia, can differentiate between several genera of actinobacteria. By combining chemotaxonomic and morphological data, the three isolates characterized by parietal type I can be assigned to the genus Streptomyces rather than the related genera such as Streptoverticillum, Kitasatoa, and Chainia. The latest, are recognized by particular structures such as verticils, sporangia, and sclerotia (Williams et al. 1989). Scan electron micrographs reveal long chains either straight for SB1 or spiral for SO1 and $\mathrm{SO} 2$ with smooth spore ornamentation and the absence of specific structures (verticils, sclerotia, synnema, and sporangia). These observations strongly suggest the affiliation of SO1, SO2, and SB1 to the genus Streptomyces.

Locci (1989) has reported that most Streptomyces species have smooth spores. Also, according to Ezra et al. (2004), the cylindrical shape of the spores exclusively characterizes Streptomyces. As the spore mass color has been widely used in Streptomyces taxonomy, our isolates should be assigned to grey, white and yellow series of Streptomyces. In addition, the Mol\% GC values were found to be high; they are $70.89 \%, 75.68 \%$, and $73.66 \%$, for SO1, $\mathrm{SO} 2$, and SB1 respectively. GC\% of the genome of microorganisms is a recommended characteristic for the standard description of microbial genera and species (Gonzalez and Saiz-Jimenez, 2005). These data are in agreement with the $\mathrm{GC} \%$ range characterizing actinobacteria, which have a GC\% greater than 55, and Locci (1989) cited that the GC\% of Streptomyces strains ranges from 68 to $78 \mathrm{~mol} \%$. Considering all these results, the isolates were assigned to Streptomyces and designated as follows: Streptomyces sp. SO1, Streptomyces sp. SO2 and Streptomyces sp. SB1.

Results obtained in this investigation are not surprising. By comparing them with other studies (Aouar et al. 2012; Xue et al. 2013; Jog et al. 2014; Anwar et al. 2016), it could be said that members of Streptomyces genus are the most common among the rhizosphere isolates. Goudjal et al. (2014), Mouloud et al. (2016), Abdelmoteleb, and Mendoza (2020) have explored rhizospheric Saharan soils. They have isolated actinobacteria, the majority of them were allowed to Streptomyces genus.

Table 2. Morphological and physiological characteristics of the isolates

\begin{tabular}{lccc}
\hline Characteristics & \multicolumn{3}{c}{ Strains } \\
\cline { 2 - 4 } $\begin{array}{l}\text { Morphological characteristics } \\
\text { Colour of spore mass }\end{array}$ & GO1 & SO2 & SB1 \\
\multicolumn{1}{c}{ Spore chain morphology } & White & $\begin{array}{c}\text { Yellowish } \\
\text { grey }\end{array}$ \\
Carbon source utilization $^{b}$ & $\begin{array}{c}\text { Spiral } \\
\text { (open) }\end{array}$ & $\begin{array}{c}\text { Spiral } \\
\text { (looped) }\end{array}$ & $\begin{array}{c}\text { Rectiflexi- } \\
\text { biles }\end{array}$
\end{tabular}

L-Arabinose

D-Fructose

Myo-inositol

D-Lactose

D-Maltose

D-Mannose

Raffinose

L-Rhamnose

Sucrose

D-Xylose

Nitrogen source utilization ${ }^{c}$

Cysteine

Tryptophan

Methionine

Degradation activities $^{d}$

Tyrosine

Casein

Xanthine

Enzyme activity ${ }^{e}$

Nitrate reduction

Growth in the presence of inhibitors ${ }^{f}$

Lysozyme $\left(50 \mu \mathrm{g} \mathrm{mL}^{-1}\right)$

$\mathrm{NaCl}(7 \%)$

Phenol $(0.1 \mathrm{w} / \mathrm{v})$

Potassium tellurite $(0.001 \% \mathrm{w} / \mathrm{v})$

Thallous acetate $(0.001 \% \mathrm{w} / \mathrm{v})$

Environmental characteristics ${ }^{g}$

$45^{\circ} \mathrm{C}$

$\mathrm{pH} 4.3$

$\begin{array}{lll}+ & + & \pm \\ + & \pm & \pm \\ + & + & - \\ + & + & - \\ - & + & - \\ + & - & \pm \\ + & + & - \\ + & \pm & - \\ + & + & - \\ - & \pm & - \\ & & \\ - & + & + \\ + & - & - \\ - & - & - \\ & & \\ - & + & + \\ + & + & + \\ - & \pm & +\end{array}$

Note: '+' = positive; '-' = negative; ' \pm ' = weakly. ${ }^{a}$ All strains were negative for melanoid pigments production and present smooth spore ornamentation. ${ }^{b}$ All strains were positive for assimilation of glucose, mannitol, glycerol, citrate, propionate and negative for assimilation of xylilol, adonitol, sorbitol, sorbose, melezitose and melibiose. ${ }^{c}$ All strains were positive for utilization of lysine, phenylalanine, asparagines, $\mathrm{KNO}_{3}$, proline, arginine, and negative for methionine utilization. ${ }^{d}$ All strains were positive for degradation of adenine, gelatin, chitin, starch, and negative for inulin degradation. ${ }^{e}$ All strains were positive for urease and $\beta$ galactosidase activities. ${ }^{f}$ All strains were positive for growth in $4 \% \mathrm{NaCl}, 10 \mu \mathrm{g} \mathrm{mL}^{-1}$ lysozyme, and negative for growth in sodium azide and crystal violet. ${ }^{g}$ All strains were positive for growth at $\mathrm{pH} 7$, at 25 and $37{ }^{\circ} \mathrm{C}$, and negative for growth at +4 and $10{ }^{\circ} \mathrm{C}$. 

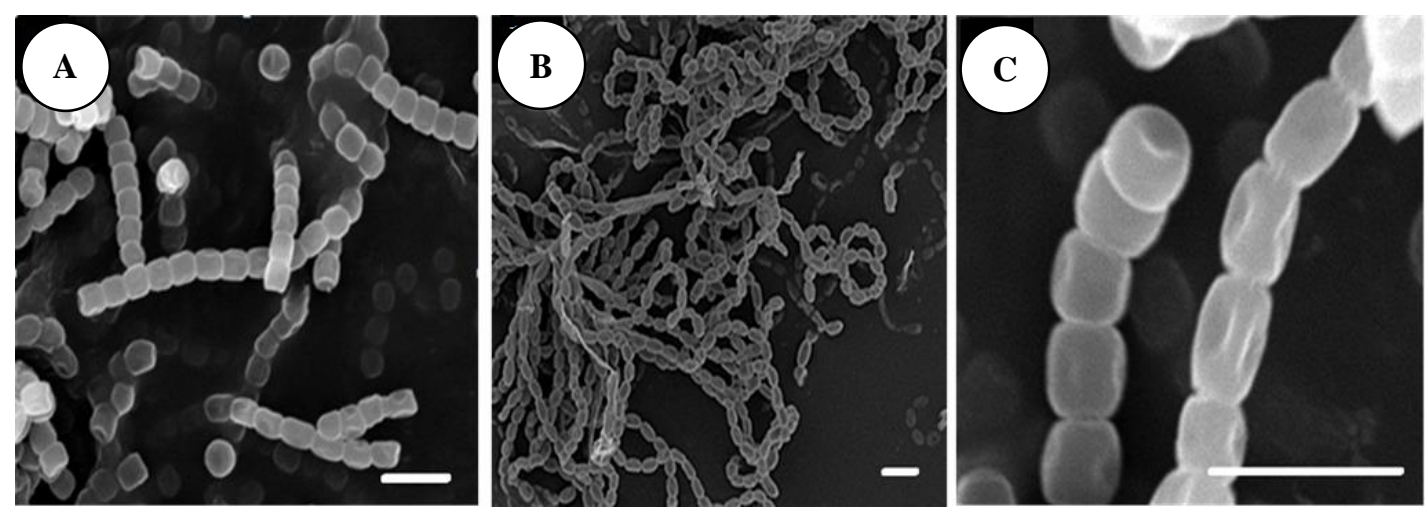

Figure 2. Scanning electron micrographs showing spores chain morphology and smooth spores ornamentation. A. Streptomyces sp. SO1; B. Streptomyces sp. SO2; C. Streptomyces sp. SB1. Bar $=2 \mu \mathrm{m}$

\section{Identification of the antagonistic isolates}

The isolates showed a variable capacity to use different sources of carbon and nitrogen, enzymatic activities, as well as growth in media containing inhibitors and under different environmental conditions. The results are shown in Table 2. According to Meyer (1989), Streptomyces strains can assimilate a vast variety of nutrient sources, except a few compounds such as inulin, xylitol, and methionine, which are infrequently used. All strains grew well between 25 and $37{ }^{\circ} \mathrm{C}$. Exceptionally, Streptomyces sp. SO1 and Streptomyces sp. SO2 grew at $45{ }^{\circ} \mathrm{C}$. Thus, Meyer (1989) indicated that the majority of Streptomyces are mesophilic except a few strains which are capable of growing at $+4^{\circ} \mathrm{C}$ or above $45^{\circ} \mathrm{C}$. The isolates grow optimally at $\mathrm{pH} 7$, which characterizes the majority of telluric Streptomyces.

A phylogenetic tree gathering the sequences of our isolates as well as those of the type strains, obtained by the BLAST, was constructed by using tree-making algorithms, neighbor-joining (NJ). The NJ methods are from the MEGA 6.0 package. Streptomyces sp. SO1, Streptomyces sp. SO2 and Streptomyces sp SB1 appear only with Streptomyces species. Thereby, the phylogenetic tree includes two clades as represented by Figure 3 .

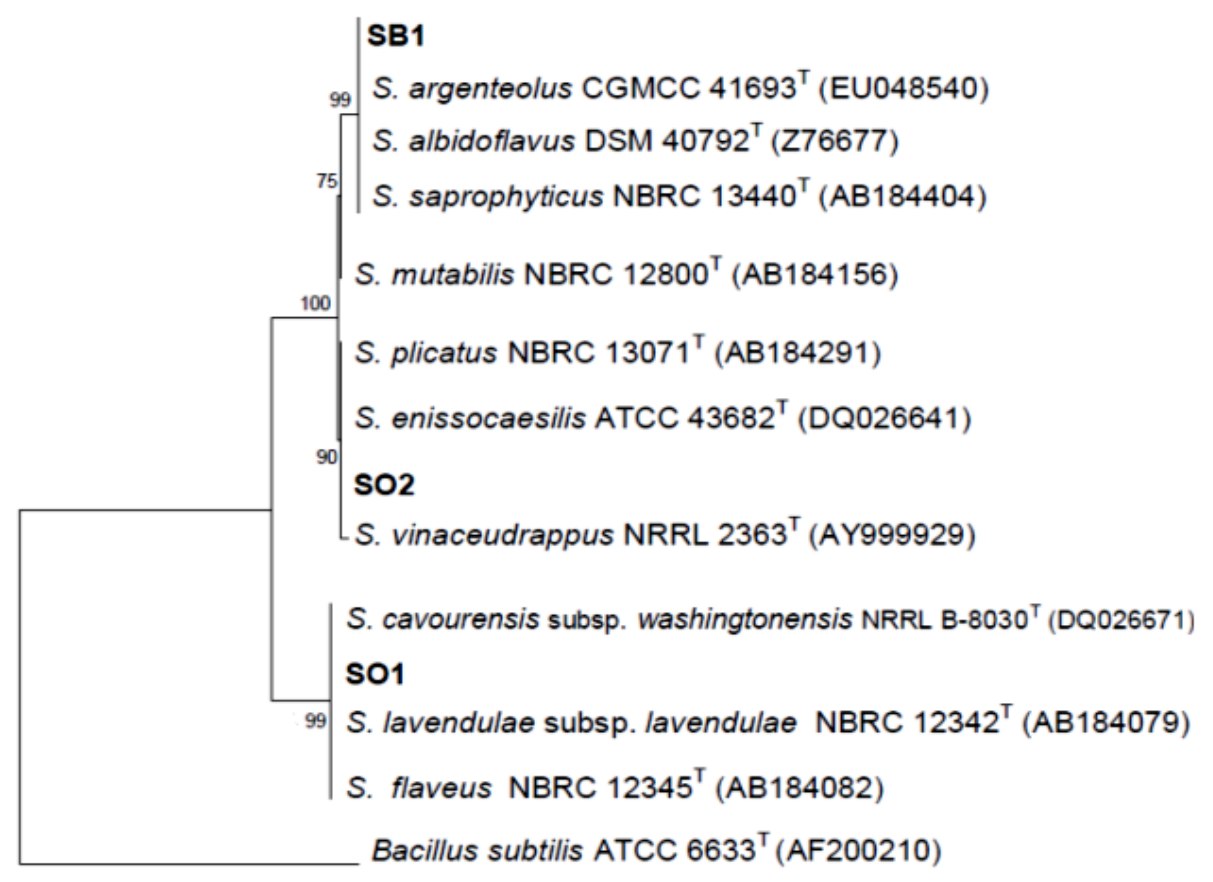

$\longmapsto .02$

Figure 3. Neighbor-joining phylogenetic tree based on 16S rRNA gene sequences showing relationship between SB1, SO1, and SO2 and their closest relatives. Bacillus subtilis ATCC $6633^{\mathrm{T}}$ was used as an outgroup. Bootstrap values based on 1000 replicates. Bar, 0.02 substitutions per nucleotide position 
The first clade supported by $99 \%$ of the bootstrap value, is regrouping the clusters of Streptomyces sp SB1 and Streptomyces sp. SO2 with their related strains. The second clade is supported by $99 \%$ replications of bootstrap, it includes the SO1 isolate and its closely related strains. Regarding previous results, phylogenetic analysis strongly supports those obtained with morphological, physiological, and chemotaxonomic identification. However, to assign them to their respective Streptomyces species, a polyphasic approach must be adopted. It involves morphological, cultural, biochemical, and physiological data in conjunction with phylogenetic analysis (Khamna et al. 2009).

The dendrogram illustrated by Figure 3 indicates that Streptomyces sp SB1 and Streptomyces sp. SO2 strains appear in the same clade supported by $100 \%$ bootstrap replicates. The first cluster, supported by $99 \%$ bootstrap value, reveals the close phylogenetic correlation between SB1 and its neighbors: Streptomyces albidoflavus DSM $40792^{\mathrm{T}}$, Streptomyces saprophyticus NBRC $13440^{\mathrm{T}}$, and Streptomyces argenteolus CGMCC $41693^{\mathrm{T}}$, in which they occupy the same phyletic line. A comparison of Streptomyces sp SB1 characters obtained in this study with data provided by Williams et al. (1989), Islam et al. (2009), and Atta et al. (2011), suggests that this strain belongs to $S$. albidoflavus species. Both show a great morphological similarity with a yellow spore mass and rectiflexibiles spore chains without melanoid pigments production. Like S. albidoflavus; SB1 uses glucose, mannitol, glycerol, cysteine, lysine, asparagine; but does not use xylitol, raffinose, rhamnose, sucrose, xylose, tryptophan, and methionine. In addition, both strains were able to grow at $\mathrm{pH}$ 4.3. Nevertheless, the two strains differ in a few characteristics such as assimilation of arabinose, maltose, and gelatin degradation. This close phylogenetic relatedness and similarity of features allowed us to refer to the strain Streptomyces sp. SB1 to S. albidoflavus.

The second cluster regroups in the same phyletic line, Streptomyces sp. SO2 with its related species Streptomyces plicatus NBRC $13071^{\mathrm{T}}$, Streptomyces enissocaesilis ATCC $43682^{\mathrm{T}}$ and Streptomyces vinaceudrapus NRLL $2336^{\mathrm{T}}$ with a bootstrap value of $99 \%$. The comparison with the $S$. enissocaesilis data reported by Sirisha et al. (2014) and Laidi et al. (2007) suggests that the characteristics of Streptomyces sp. SO2 matched with those of $S$. enissocaesilis. Their color spore mass is white with spiral spores chain morphology. The two strains assimilate glucose, arabinose, inositol, lactose, maltose, mannitol, glycerol, raffinose, sucrose, lysine, and citrate. Both of them were negative for the assimilation of mannose and tryptophan. Same as S. enissocaesilis, Streptomyces sp. SO2 degrades casein, starch and gelatin. Both strains do not assimilate fructose, rhamnose, and xylose. They show urease activity but not nitrate reduction. Unlike $S$. enissocaesilis, Streptomyces sp. SO2 was able to grow at $45{ }^{\circ} \mathrm{C}$. Probably, our strain is adapted to the high temperatures of the arid climate of the Algerian Sahara. Moreover, it has been found by Sirisha et al. (2014) that $S$. enissocaesilis AUBT-1404 presents a GC\% of 76.2\%, which is quite near to that of SO2. As a result of these comparisons, the strain $\mathrm{SO} 2$ should be assigned to $S$. enissocaesilis.

Streptomyces sp. SO1 appears on a distinctive cluster with three representative species: Streptomyces cavourensis subsp. cavourensis NRRL B-8030 ${ }^{\mathrm{T}}$, Streptomyces lavendulae subsp. lavendulae NBRC $12342^{\mathrm{T}}$ and Streptomyces flaveus NBRC $12345^{\mathrm{T}}$ with a high value of bootstrap (99\%) replicates. Data reported by Williams et al. (1989) and Lee et al. (1995) on S. flaveus, showed a high similarity level with Streptomyces sp. SO1. Thus, both strains were positive for the assimilation of glucose, arabinose, fructose, inositol, mannose, mannitol, raffinose, rhamnose, sucrose, citrate, lysine, tryptophan, and phenylalanine. Also, they were able to hydrolyze starch and gelatin, to reduce nitrate, and to grow in the potassium tellurite inhibitor. Unlike $S$. flaveus, Streptomyces sp. SO1 grew at $45^{\circ} \mathrm{C}$, which may be due to its isolation region characterized by high temperatures. Therefore, this polyphasic identification suggests that the strain SO1 belongs to S. flaveus.

Several studies on the antagonistic activity of rhizospheric Streptomyces have been documented (Khamna et al. 2009; Anwar et al. 2016; Aouar et al. 2016; Sharma and Manhas, 2020) since it is the largest and the active genus among actinobacteria, and $75 \%$ of biologically active compounds are produced by members of this genus (Singh et al. 2019). However, to our knowledge, very few publications are available in the literature that explores antagonistic activity of $S$. albidoflavus, S. enissocaesilis, and most particularly $S$. flaveus. Our findings are in agreement with those obtained by Laidi et al. (2007). They found that $S$. enissocaesilis strain RAF10, showed good antifungal (against Fusarium, Botrytis, and Aspergillus) and antibacterial activities (against both Gram-positive and Gram-negative bacteria). In this study, S. enissocaesilis SO2 exhibited the most significant inhibition zone against Gram-negative bacteria, which is in disagreement with that obtained by Sinisha et al. (2014), they found that $S$. enissocaesilis exhibits very low activity against Gramnegative bacteria. The only strain that inhibited all the phytopathogens tested was $S$. flaveus SO1. This is supported by another study, showing the inhibition capacity of Rhizoctonia solani by a low concentration of S. flaveus filtrate (Lee et al. 1995). Antagonistic capacities exhibited by $S$. albidoflavus, corroborate with those obtained by Atta et al. (2011), they reveal the absence of antagonism towards Gram-negative bacteria, but the presence of an interesting activity against $F$. oxysporum, A. niger, and $A$. flavus. Also, Brezeziska et al. (2013) confirmed the antifungal potential of $S$. albidoflavus.

\section{Indol-3-acetic acid quantification}

The colorimetric assay revealed that all strains are able to produce IAA when the medium is amended with Ltryptophan (L-Trp). The IAA amounts ranged from 41.88 to $107.48 \mu \mathrm{g} \mathrm{mL} \mathrm{m}^{-1}$. S. flaveus SO1 recorded the greatest quantity. As presented in Figure 4, the results suggest strongly that IAA production by $S$. flaveus $\mathrm{SO} 1$ and $S$. enissocaesilis $\mathrm{SO} 2$ was not affected by L-Trp concentration (P >0.05). Nevertheless, the IAA produced by $S$. albidoflavus SB1 was positively and significantly $(\mathrm{P}<$ $0.05)$ correlated with L-Trp concentration. Interestingly, all 
our selected isolates produced IAA. It has been observed that aptitude to produce IAA is a frequent trait among antagonistic species of Streptomyces (Abbasi et al. 2019).

All isolates require the presence of L-Trp, suggesting that they use a pathway L-Trp-dependent for the IAA synthesis. Among the three strains, IAA production was greater for S. flaveus SO1; probably, this strain was already adapted to high concentrations of L-Trp in its rhizosphere, which enhance IAA biosynthesis. These results corroborate with other reported studies (Qin et al. 2015; Legault et al. 2011; Aouar et al. 2016). Conversely, de Oliveira et al. (2010) have reported that some actinobacteria are able to produce IAA without L-Trp, possibly due to the use of another synthesis pathway. Anwar et al. (2016), have found that $S$. enissocaesilis TA-3 produced $69.26 \mu \mathrm{g} \mathrm{mL} \mathrm{m}^{-1}$ of IAA, which is equivalent to that obtained by $S$. enissocaesilis $\mathrm{SO} 2$.

Several studies have explored the IAA production by Streptomyces species. Compared to other studies, our results are comparable to those found by Khamna et al. (2009) (5.5-144 $\mathrm{g} \mathrm{mL}^{-1}$ ) and Goudjal et al. (2016) (35.9$117 \mu \mathrm{g} \mathrm{mL}^{-1}$ ); but lower than those obtained by Chaiharn and Lumyong (2011) (2.55-291.97 $\left.\mu \mathrm{g} \mathrm{mL}^{-1}\right)$. However, they are higher than those reported by Qin et al. (2015) (2.21-9.14 $\left.\mu \mathrm{g} \mathrm{mL}^{-1}\right)$ and Abbasi et al. (2019) (7.0-40.9 $\left.\mu \mathrm{g} \mathrm{mL}^{-1}\right)$.

\section{Siderophore production and kinetics of catechols}

CAS assay showed that only S. albidoflavus SB1 and $S$. flaveus SO1 (66\%) produced siderophores. According to the specific tests, both strains produced catechol-type of siderophores in a range of 32.01 to $160.63 \mu \mathrm{g} \mathrm{mg}$ bact. $\mathrm{DW}^{-1}$ (Figure 5). Several reports have shown that Streptomyces sp. from many crop rhizosphere soils have this ability (Khamna et al. 2009; Aouar et al. 2016; Goudjal et al. 2016; Warrad et al. 2020). However, only a few studies have reported the ability of $S$. enissocaesilis strains to produce siderophores, for example, $S$. enissocaesilis TA3 (Anwar et al. 2016) and S. enissocaesilis IC10 (Abbasi et al. 2019). To our knowledge, the siderophore production by S. albidovlavus and S. flaveus has not been reported.
Another important characteristic of rhizobacteria that promote plant growth is the production of siderophores, they could antagonize fungi by iron chelation. Moreover, microbial siderophores may be utilized by plants as an iron source. Usually, actinobacteria can elaborate more than one type of siderophores simultaneously (e.g., catechols, hydroxamates, and salicylates). Although, hydroxamates and catechols are the most important. In this study, specific assays demonstrated that both positive strains produced only catechol-type siderophores. Our results are in concordance with those of Gangwar et al. (2012), they found that the catechols producing isolates represent the largest proportion. In contrast, Lee et al. (2012) reported that only $20 \%$ of actinobacterial isolates produced catechols while all produced hydroxamates. Results obtained by Lee et al. (2012), suggest that catechols are only produced at times of severe iron starvation and they found that the proportions of actinobacterial isolates producing catechols were only $3 \%$. Production started after $24 \mathrm{~h}$ and catechols accumulation increased with time.

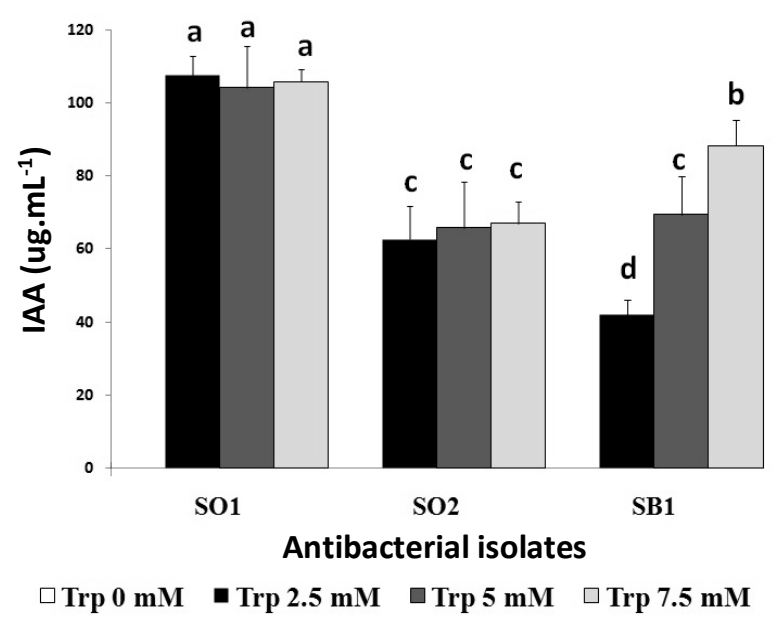

Figure 4. Indole-3-acetic acid production with different concentrations of L-Trp

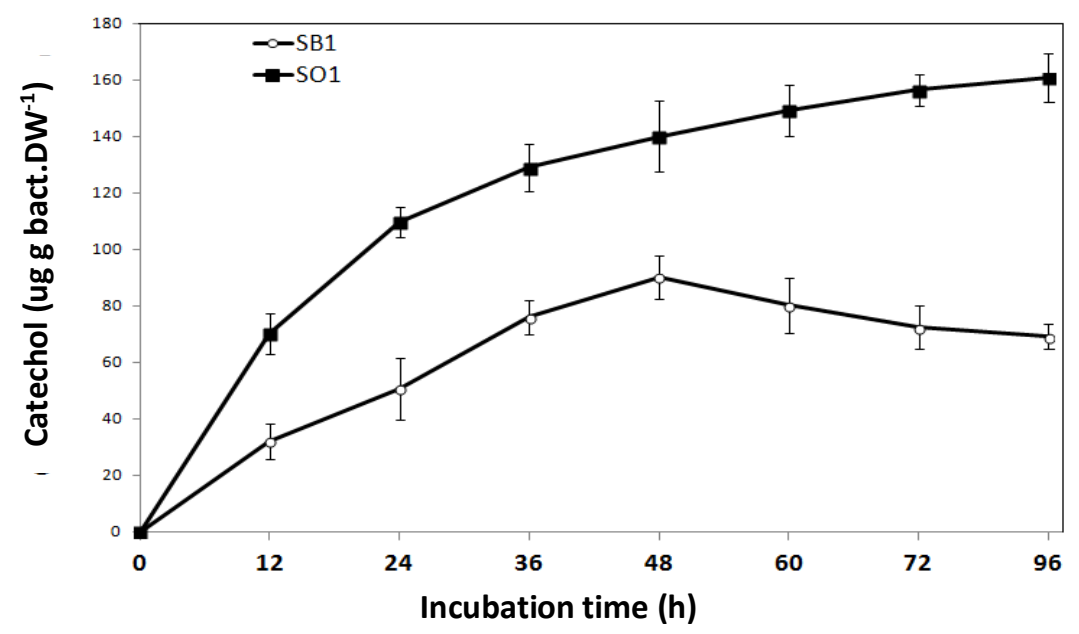

Figure 5. Kinetics of catechols production by Streptomyces albidoflavus SB1 and S. flaveus SO1, as a function of time. 


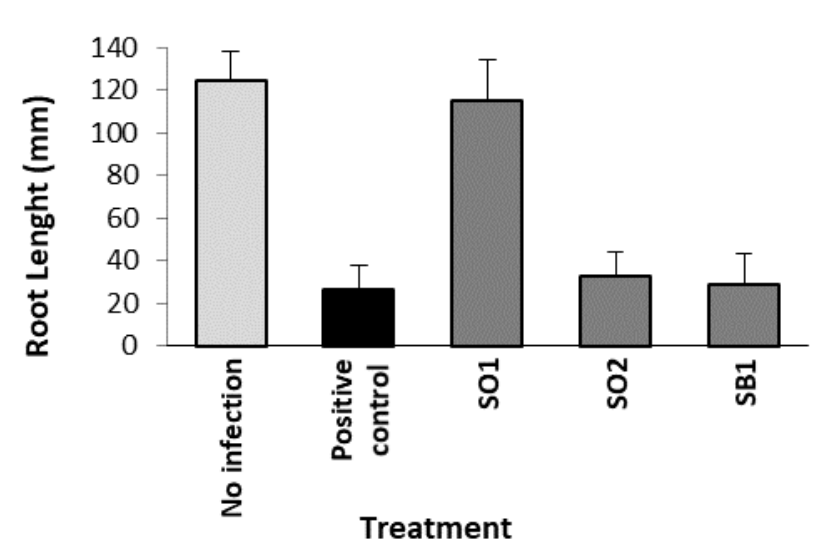

Figure 6. Biocontrol assay against Streptomyces scabiei

Thus, S. albidoflavus SB1 production reached its peak after $60 \mathrm{~h}$ and then was decreasing slowly, while S. flavus SO1 production continued to increase after $72 \mathrm{~h}$. Kinetics of siderophores studied by Dimkpa, et al. (2009), is in agreement with our findings, they demonstrated their positive detection as early as $24 \mathrm{~h}$. Additionally, similar kinetics of SB1 was reported for the Streptomyces griseus Lac1 strain (Aouar et al. 2016).

\section{Phosphate solubilization}

It has been established that phosphate is a plant growthlimiting element. Thus, several studies have focused on the capacity of microorganisms to solubilize phosphate (Sezen et al. 2016). Which have shown their efficiency in improving the accessibility of phosphate to plants by laboratory, greenhouse, or field trials (Salcedo et al. 2014). Nevertheless, actinobacteria have been extensively studied for their capacity to produce new antibiotics, but few studies have explored their aptitude to solubilize phosphate (Sudiana et al. 2020). In this study, a qualitative assessment of phosphate solubilization showed the apparition of a clear solubilization zone around colonies of S. flaveus SO1 and $S$. enissocaesilis SO2. The recorded diameters were $0.7 \pm 0.1 \mathrm{~mm}$ and $0.9 \pm 0.1 \mathrm{~mm}$, respectively. Our results corroborate with those of Franco-Correra et al. (2010), they found that phosphate solubilizing ability was widely exhibited by actinobacteria isolates. However, it has been found by Qin et al. (2015) and Aouar et al. (2016) that the greater part of their isolates was unable to solubilize phosphate.

\section{Biocontrol assay}

As presented in Figure 6, only S. flaveus SO1 was able to inhibit $S$. scabiei in vivo. It demonstrates no significant difference $(\mathrm{p}<0.05)$ with negative control. Also, the results revealed that no significant difference $(p<0.05)$ was recorded between $S$. enissocaesilis $\mathrm{SO} 2, \quad S$. albidoflavus SB1, and positive control. Biocontrol trial showed that $S$. flaveus SO1 was able to antagonize significantly $S$. scabiei and to suppress symptoms of common scab, especially root necrosis (Figure 7).

Mechanisms of biocontrol include antibiotic production, secretion of hydrolytic enzymes, production of siderophores, and niche exclusion. It is clear that our isolates act by antibiosis, which results in clear lysis zones around bacterial colonies as shown in Figure 1 a. According to the literature, there are already some antibiotics elaborated by Streptomyces that are used against bacterial plant diseases such as streptomycin synthesized by Streptomyces griseus to control Xanthomonas oryzae and Pseudomonas lachrymans (Copping and Menn 2000). It is evident that one of the mechanisms used by $S$. flaveus SO1 is antibiosis, as this strain has already shown interesting antagonistic activity in vitro against this pathogen. Furthermore, it has been stated that antibiosis is the main mechanism in biocontrol since isolates that are active in vitro are also effective in soil environment (Goudjal et al. 2014). However, this antibiosis does not accept the involvement of other plant growth-promoting properties, considering that this strain is also capable to produce siderophores and to solubilize phosphate. Streptomyces flaveus SO1 isolated from an arid soil collected from a region characterized by a Saharan climate, is a rhizospheric strain which means that it is already adapted to the different influences and interactions characterizing the rhizosphere. Furthermore, this strain presents PGPR characteristics in addition to its antagonism against certain bacteria and phytopathogenic fungi. All these promising properties qualify it to be a good candidate as a biocontrol agent and plant growth promoter, especially in arid regions.
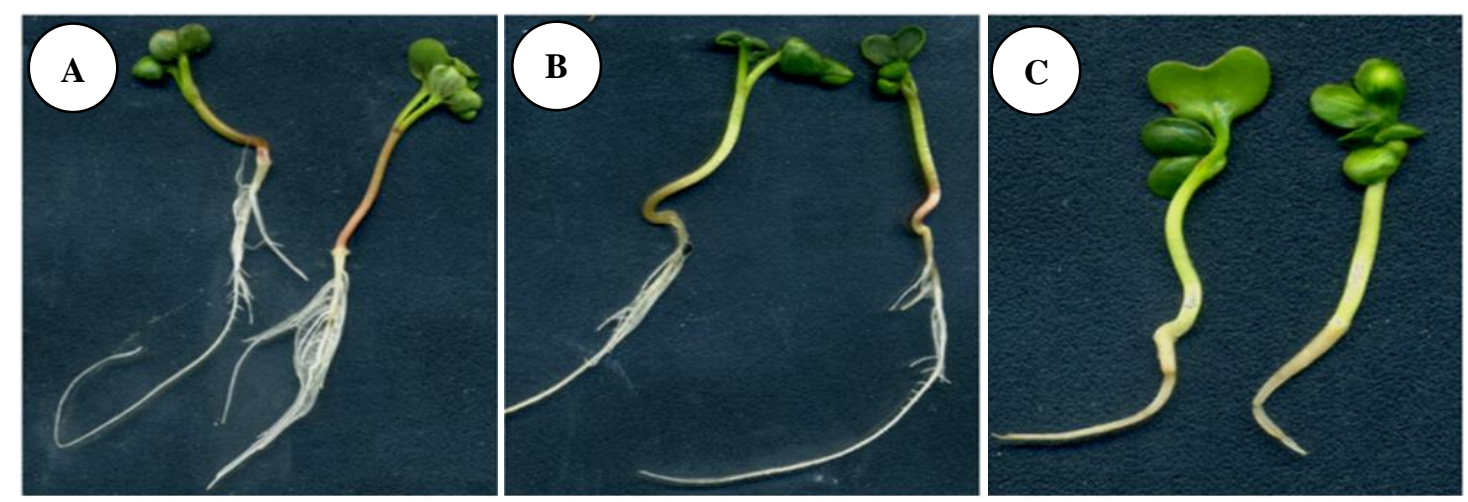

Figure 7. Effect of SO1 on the development of radish seedlings. A. Radish seedlings no treated (negative control); B. Radish seedlings treated with S. scabiei and SO1; C. Radish seedlings treated with S. scabiei (positive control) 
In the present study, the enhancement of root growth cannot be related to the IAA effect, because the medium has not been amended with L-Trp, especially since these strains require L-Trp as precursor to synthesize IAA. The effect of IAA, produced by actinobacterial strains, on plant growth has already been explored. Therefore, Merzaeva and Shirokikh (2010) found that IAA produced by actinobacteria improves rye seed germination and promotes seedling growth. In addition, Goudjal et al. (2014) have reported that the IAA extracted from Streptomyces sp. exhibited a promoting effect on seeds germination and root growth of tomatoes seedlings.

From the research that has been done, it is possible to conclude that three interesting rhizospheric isolates were selected from Algerian Saharan soils. Their pronounced antagonistic profiles highlight their potential as antibacterial and antifungal agents against plant phytopathogens. Particularly they have been able to degrade chitin, which can also contribute to the antagonistic capacity against fungi. These isolates belong to the genus Streptomyces and have been identified as $S$. flaveus SO1, S. enissocaesilis SO2, and S. albidoflavus SB1. Among these isolates, Streptomyces flavus SO1 has Inhibited in vitro all tested pathogens including bacteria and fungi. In addition, it has demonstrated the potential to produce IAA, to elaborate siderophores type catechol, to solubilize phosphate, and to antagonize $S$. scabiei in vivo. These characteristics confer its potential as a promising candidate to enhance plant growth and to control plant pathogens. Therefore, this preliminary study must be completed; it requires further investigations to evaluate the antagonistic capacity in the field and to elucidate the other processes implicated in plant growth promoting and biocontrol.

\section{ACKNOWLEDGEMENTS}

The authors would like to thank their colleagues Dr. Mohamed Chikara Bouziani and Dr. Fateh Merouane from Larbi Ben M'Hidi University, Algeria for their technical assistance.

\section{REFERENCES}

Abbasi S, Safaie N, Sadeghi A, Shamsbakhsh M. 2019. Streptomyces strains induce resistance to Fusarium oxysporum f. sp. lycopersici race 3 in tomato through different molecular mechanisms. Front Microbial. DOI: 10.3389/fmicb.2019.01505.

Abdelmoteleb A, Mendoza DG. 2020. A novel Streptomyces rhizobacteria from desert soil with diverse anti-fungal properties. Rhizosphere. DOI: 10.1016/j.rhisph.2020.100243.

Anwar S, Ali B, Sajid I. 2016. Screening of rhizospheric actinomycetes for various in-vitro and in-vivo plant growth-promoting (PGP) traits and for agroactive compounds. Front Microbiol. DOI: 10.3389/fmicb.2016.01334.

Aouar L, Lerat S, Boulahrouf A, Beaulieu C. 2016. Bacterial antagonism and plant growth-promoting traits of actinobacterial strains previously Selected for their antifungal properties. Transylv Rev 10: 2408-2417.

Aouar L, Lerat S, Ouffroukh A, Boulahrouf A, Beaulieu C. 2012 Taxonomic identification of rhizospheric actinobacteria isolated from Algerian semi-arid soil exhibiting antagonistic activities against plant fungal pathogens. Can J Plant Pathol 34 (2): 165-176. DOI: 10.1080/07060661.2012.681396.

Apsari PP, Budiarti S, Wahyudi AT. 2019. Actinomycetes of rhizosphere soil producing antibacterial compounds against urinary tract infection bacteria. Biodiversitas $20 \quad$ (5): $1259-1265$ DOI: 10.13057/biodiv/d200504.

Atkin CL, Neilands JB, Phaff HJ. 1970. Rhodotorulic acid from species of Leucosporidium, Rhodosporidium, Rhodotorula, Sporidiobolus, Sporobolomyces and a new alanine-containing ferrichrome from Cryptococcus melibiosum. J Bacteriol 103: 722-733.

Atta HM, Bahobail AS, El-Sehrawi, MH. 2011. Studies on isolation, classification and phylogenetic characterization of antifungal substance produced by Streptomyces albidoflavus-143. NY Sci J 4: 40-53.

Barka EA, Vatsa P, Sanchez L, Gaveau-Vaillant N, Jacquard C, Klenk HP et al. 2016. Taxonomy, physiology, and natural products of Actinobacteria. Microbiol Mol Biol Rev 80 (1): 1-43. doi: 10.1128/MMBR.00019-15.

Becker B, Gordon RE, Lechevalier HA, Lechevalier MP. 1964. Rapid differentiation between Nocardia and Streptomyces by paper chromatography of whole-cell hydrolysates. Appl Microbial 12: 42 1423.

Boudemagh A, Kitouni M, Boughachiche F, Hamdiken H et al. 2005. Isolation and molecular identification of actinomycetes microflora, of some Saharan soils of south east Algeria (Biskra, El-Oued and Ourgla) study of antifungal activity of isolated strains. J Med Mycol 15: 39-44. DOI: 10.1016/j.mycmed.2004.12.004.

Boudjeko T, Tchinda RA, Zitouni M, Nana JA, Lerat S, Beaulieu C. 2017. Streptomyces cameroonensis sp. nov., a geldanamycin producer that promotes Theobroma cacao growth. Microbes Environ 32: 24-31. DOI: 10.1264/jsme2.ME16095.

Brzezinska MS, Jankiewicz U, Burkowska A. 2013. Purification and characterization of Streptomyces albidoflavus antifungal components. Appl Biochem Microbiol 49 (5): 451-457. DOI: 10.1134/S0003683813050025.

Chaabane-Chaouch F, Bouras N, Mokrane S, Bouznada K, Zitouni A, Pötter G, Spröer C, Klenk HP, Sabaou N. 2017. Planomonospora algeriensis sp. nov., an actinobacterium isolated from a Saharan soil of Algeria. Antonie van Leeuwenhoek 110 (2): 245-252. DOI: 10.1007/s10482-016-0795-1.

Chaiharn M, Lumyong S. 2011. Screening and optimization of indole-3acetic acid production and phosphate solubilization from rhizobacteria aimed at improving plant growth. Curr Microbiol 62: 173-181. DOI: 10.1007/s00284-010-9674-6.

Copping LG, Menn JJ. 2000. Biopesticides: a review of their action, applications and efficacy. Pest Manage Sci 56: 651-676.

de Oliveira MF, da Silva MG, Van Der Sand ST. 2010. Antiphytopathogen potential of endophytic actinobacteria isolated from tomato plants (Lycopersicon esculentum) in southern Brazil, and characterization of Streptomyces sp. R18 (6), a potential biocontrol agent. Res Microbiol 161: 565-572. DOI: 10.1016/j.resmic.2010.05.008

Dimkpa CO, Merten D, Svatoš A, Büchel G, Kothe E. 2009. Metal induced oxidative stress impacting plant growth in contaminated soil is alleviated by microbial siderophores. Soil Biol Biochem 41: 154162. DOI: 10.1016/j.soilbio.2008.10.010.

Djinni I, Defant A, Kecha M, Mancini I. 2019. Actinobacteria derived from Algerian ecosystems as a prominent source of antimicrobial molecules. Antibiotics. DOI: 10.3390/antibiotics8040172.

Ezra D, Castillo UF, Strobel GA. 2004. Coronamycins, peptide antibiotics produced by a verticillate Streptomyces sp. (MSU-2110) endophytic Monstera. Microbiol 150: 785-793. doi: 10.1099/mic.0.26645-0.

Fisher MC, Hawkins NJ, Sanglard D, Gurr SJ. 2018. Worldwide emergence of resistance to antifungal drugs challenges human health and food security. Science 360: 739-742. DOI: 10.1126/science.aap7999.

Franco-Correa M, Quintana A, Duque C, Suarez C, Rodríguez MX, Barea JM. 2010. Evaluation of actinomycete strains for key traits related with plant growth promotion and mycorrhiza helping activities. Appl Soil Ecol 45 (3): 209-217. DOI: 10.1016/j.apsoil.2010.04.007.

Gonzalez JM, Saiz-Jimenez C. 2005. A simple fluorimetric method for the estimation of DNA-DNA relatedness between closely related microorganisms by thermal denaturation temperatures. Extremophiles 9: 75-79. DOI: 10.1007/s00792-004-0417-0. 
Gangwar M, Dogra S, Gupta UP, Kharwar RN. 2014. Diversity and biopotential of endophytic actinomycetes from three medicinal plants in India. Afri J Microbiol Res 8 (2), 184-191. DOI: 10.5897/AJMR2012.2452

Goredema N, Ndowora T, Shoko R, Ngadze E. 2020. In vitro suppression of pathogenic fungi by Streptomyces spp. Afr Crop Sci J 28 (2): 141149 .

Goudjal Y, Zamoum M, Meklat A, Sabaou N, Mathieu F, Zitouni A. 2016. Plant-growth-promoting potential of endosymbiotic actinobacteria isolated from sand truffles (Terfezia leonis Tul.) of the Algerian Sahara. Ann Microbiol 66 (1): 91-100. DOI: 10.1007/s13213-015-1085-2.

Goudjal Y, Toumatia O, Yekkour A, Sabaou N, Mathieu F, Zitouni A 2014. Biocontrol of Rhizoctonia solani damping-off and promotion of tomato plant growth by endophytic actinomycetes isolated from native plants of Algerian Sahara. Microbiol Res 169 (1): 59-65. DOI: 10.1016/j.micres.2013.06.014.

Hider RC, Kong X, 2010. Chemistry and biology of siderophores. Nat Prod Rep 27: 637-657.

Islam MR, Jeong YT, Ryu YJ, Song CH, Lee YS. 2009. Isolation, identification and optimal culture conditions of Streptomyces albidoflavus $\mathrm{C} 247$ producing antifungal agents against Rhizoctonia solani AG2-2. Mycobioloy 37 (2): 114-120.

Jog R, Pandya M, Nareshkumar G, Rajkumar S. 2014. Mechanism of phosphate solubilization and antifungal activity of Streptomyces spp. isolated from wheat roots and rhizosphere and their application in improving plant growth. Microbiology 160 (4): 778-788. DOI: $10.1099 / \mathrm{mic} .0 .074146-0$.

Khalil M, Lerat S, Beaudoin N, Beaulieu C. 2019. The plant pathogenic bacterium Streptomyces scabiei degrades the aromatic components of potato periderm via the $\beta$-ketoadipate pathway. Front Microbiol. DOI: 10.3389/fmicb.2019.02795

Khamna S, Yokot A, Lumyong S. 2009. Actinomycetes isolated from medicinal plant rhizosphere soils: diversity and screening of antifungal compounds, indole-3-acetic acid and siderophore production. World J Microbiol Biotechnol 25: 649-655. DOI 10.1007/s1 1274-008-9933-x.

Khamna S, Yokota A, Peberdy JF, Lumyong S. 2010. Indole-3-acetic acid production by Streptomyces sp. isolated from some Thai medicinal plant rhizosphere soils. EurAsian J BioSci 4 (1): 23-32.

Lahoum A, Sabaou N, Bijani C, Bouras N, Pont F, Snini SP, Mathieu F. 2019. Antimicrobial activities of novel bipyridine compound produced by a new strain of Saccharothrix isolated from Saharan soil Saudi Pharm J 27: 56-65. DOI: 10.1016/j.jsps.2018.07.019.

Laidi FR, Elshafei A, Saker M, Bengraa C, Hacene H. 2007. Screening, isolation and characterization of a novel antimicrobial producing actinomycete, strain RAF 10. Biotechnol 6 (4): 489-496.

Lechevalier MP, Lechevalier HA. 1980. The chemotaxonomy of actinomycetes. In: Dietz A, Thayer DW (eds.) Actinomycete Taxonomy (Special Publication 6), Arlington, Virginia.

Lee J, Postmaster A, Soon HP, Keast D, Carson KC. 2012. Siderophore production by actinomycetes isolates from two soil sites in Western Australia. Biometals 25: 285-296. DOI: 10.1007/s10534-011-9503-9.

Lee JY, Kim BS, Hwang BK. 1995. Numerical Identification of Streptomyces flaveus producing antibiotic substances inhibitory to plant pathogenic fungi. J Microbiol Biotechnol 5 (6): 324-334

Lee N, Kim W, Hwang S, Lee Y, Cho S, Palsson B, Cho BK. 2020. Thirty complete Streptomyces genome sequences for mining novel secondary metabolite biosynthetic gene clusters. Scientific data 7 (1) 1-9. DOI: 10.6084/m9.figshare.11791323.

Legault G, Lerat S, Nicolas P, Beaulieu C. 2011. Tryptophan regulates thaxtomin A and indole-3-acetic acid production in Streptomyces scabiei and modifies its interactions with radish seedlings. Phytopathol 101: 1045-1051. DOI: 10.1094/PHYTO-03-11-0064.

Liu D, Yan R, Fu1 Y, Wang X, Zhang J, Xiang W. 2019. Antifungal, Plant Growth-promoting, and Genomic Properties of an Endophytic Actinobacterium Streptomyces sp. NEAU-S7GS2. Front Microbiol. DOI: $10.3389 /$ fmicb.2019.02077.

Locci R. 1989. Streptomyces and related genera. In: Williams ST, Sharpe ME, Holt JG (eds.) Bergey's manual of systematic bacteriology, Williams \& Wilkins, Baltimore.

Meklat A, Bouras N, Zitouni A, Mathieu F, Lebrihi A, Schumann P, Sproer C, Klenk HP, Sabaou N. 2012. Actinopolyspora algeriensis $\mathrm{sp}$ nov., a novel halophilic actinomycete isolated from Saharan soil. Extremophiles 16: 771-776.DOI: 10.1007/s00792-012-0473-9.
Merzaeva OV, Shirokikh IG. 2010. The production of auxins by the endophytic bacteria of winter rye. Appl Biochem Microbiol 46 (1): 44-50. DOI: $10.1134 /$ S0003683810010072.

Meyer J. 1989. Genus Nocardiopsis Meyer 1976, 487 $\mathrm{AL}$. In: Williams ST, Sharpe ME, Holt JG (eds) Bergey's manual of systematic bacteriology, The Williams \& Wilkins, Baltimore.

Mohamed H, Miloud B, Zohra F, García-Arenzana JM, Veloso A, Rodríguez-Couto S. 2017. Isolation and characterization of Actinobacteria from Algerian Sahara soils with antimicrobial activities. Int J Mol Cell Med 6: 109-120.

Mohandas S, Poovarasan S, Panneerselvam P, Saritha B, Upreti KK, Kamal R et al. 2013. Guava (Psidium guajava L.) rhizosphere Glomus mosseae spores harbor actinomycetes with growth-promoting and antifungal attributes. Sci Hortic 150: 371-376. DOI: 10.1016/j.scienta.2012.11.019.

Mouloud G, Samir M, Hani B, Daoud H. 2016. Biocontrol of wheat Fusarium Head Blight (FHB) by Streptomyces spp. isolated from the rhizosphere of Astragalus gombo Coss. \& Dur. and Ononis angustissima Lam. Am Euras J Agric Environ Sci 15: 2499-2511.

Putrie RFW, Aryantha INP, Iriawati I, Antonius S. 2020. Diversity of endophytic and rhizosphere bacteria from pineapple (Ananas comosus) plant in semi-arid ecosystem. Biodiversitas 21 (7): 30843093. DOI: 10.13057/biodiv/d210728.

Qin S, Miao Q, Feng WW, Wang Y, Zhu X, Xing K, Jiang JH. 2015. Biodiversity and plant growth-promoting traits of culturable endophytic actinobacteria associated with Jatropha curcas L. growing in Panxi dry-hot valley soil. Appl Soil Ecol 93: 47-55. DOI: 10.1016/j.apsoil.2015.04.004.

Rizvi RZ, Wahab A, Pirzada ZA. 2014. Screening and identification of aquatic bacteriocinogenic Bacillus strains inhibiting clinical methicillin-resistant Staphylococcus aureus and vancomycin-resistant Enterococcus from Pakistan. Asian J Pharm Clin Res 17: 53-56.

Sadeghi A, Karimi E, Dahaji PA, Javid MG, Dalvand Y, Askari H. 2012. Plant growth-promoting activity of an auxin and siderophore producing isolate of Streptomyces under saline soil conditions. World J Microbiol Biotechnol 28 (4): 1503-1509.

Saker R, Bouras N, Zitouni A, Ghoul M, Rohde M, Schumann P et al. 2014. Mzabimyces algeriensis gen. nov., sp. nov., a halophilic filamentous actinobacterium isolated from a Saharan soil, and proposal of Mzabimycetaceae fam. nov. Antonie van Leeuwenhoek 106 (5): 1021-1030.

Salcedo LDP, Prieto C, Correa MF. 2014. Screening phosphate solubilizing actinobacteria isolated from the rhizosphere of wild plants from the Eastern Cordillera of the Colombian Andes. Afr J Microbiol Res 8 (8): 734-742.DOI: 10.5897/AJMR2013.5940.

Ser HL, Ab Mutalib NS, Yin WF, Goh BH, Lee LH, Chan KG. 2018. Genome sequence of Streptomyces antioxidants MUSC 164T isolated from mangrove forest. Prog Microbes Mol Biol. DOI: 10.36877/pmmb.a0000001

Sezen A, Ozdal M, Koc K, Algur OF. 2016. Isolation and characterization of plant growth-promoting rhizobacteria (PGPR) and their effects on improving growth of wheat. J Appl Biologic Sci 10 (1): 41-46.

Sharma M, Manhas RK. 2020. Purification and characterization of salvianolic acid B from Streptomyces sp. M4 possessing antifungal activity against fungal phytopathogens. Microbiol Res. DOI: 10.1016/j.micres.2020.126478.

Shirling ET, Gottlieb D. 1966. Methods for characterization of Streptomyces species. Intl J Syst Bacteriol 16 (3): 313-340.

Singh LS, Sharma H, Sahoo D. 2019. Actinomycetes from Soil of Lachung, a pristine high altitude region of Sikkim Himalaya, their antimicrobial potentiality and production of industrially important enzymes. Adv Microbiol 9: 750-773.DOI: 10.4236/aim.2019.98046.

Sirisha B, Haritha R, Jagan Mohan YSYV, Sawath A, Ramana T. 2014. Molecular characterization of marine Streptomyces enissocaesilis capable of L-asparaginase production. Bacteriol J 4 (1): 1-11.

Subramaniam G, Thakur V, Saxena RK, Vadlamudi S, Purohit S, Kumar V, Rathore A, Chitikineni A, Varshney RK. 2020. Complete genome sequence of sixteen plant growth-promoting Streptomyces strains. Sci Rep 10 (1): 1-13. DOI: 10.1038/s41598-020-67153-9.

Sudiana IM, Putri A, Napitupulu TP, Purnaningsih I, Kanti A. 2020. Growth inhibition of Fusarium solani and $F$. oxysporum by Streptomyces sasae TG01, and its ability to solubilize insoluble phosphate. Biodiversitas 21 (2): 429-435. DOI: 10.13057/biodiv/d210201 
Suwan N, To-anun C, Soytong K, Nalumpang S. 2012. Evaluation of Streptomyces-biofungicide to control chili anthracnose in pot experiment. J Agri Tec 8 (5): 1663-1676.

Tamura K, Stecher G, Peterson D, Filipski A, Kumar S. 2013. MEGA6: Molecular evolutionary genetics analysis version 6.0. Mol Biol Evol 30: 2725-2729.

Vurukonda SSKP, Giovanardi D, Stefani E. 2018. Plant growthpromoting and biocontrol activity of Streptomyces spp. as endophytes. Intl J Mol Sci. doi:10.3390/ijms19040952.

Warrad M, Hassan YM, Mohamed MS, Hagagy N, Al-Maghrabi OA et al. 2020. A Bioactive fraction from Streptomyces sp. enhances maize tolerance against drought stress. J Microbiol Biotechnol 30 (8): 11561168. DOI: $10.4014 / \mathrm{jmb} .2003 .03034$

Williams ST, Goodfellow M, Anderson G. 1989. Genus Streptomyces Waksman and Henrici 1943, 339 $\mathrm{AL}$. In: Williams ST, Sharpe ME,
Holt JG (eds) Bergey's manual of systematic bacteriology, Williams \& Wilkins, Baltimore.

Williams ST, Goodfellow M, Alderson G, Wellington EMH, Sneath PHA, Sackin, MJ. 1983. Numerical classification of Streptomyces and related genera. J Gen Microbiol 129: 1743-1813.

Xue L, Xue Q, Chen Q, Lin C, Shen G, Zhao J. 2013. Isolation and evaluation of rhizosphere actinomycetes with potential application for biocontrol of Verticillium wilt of cotton. Crop Prot 43: 231-240. DOI: 10.1016/j.cropro.2012.10.002

Yadav AN, Verma P, Kumar S, Kumar V, Kumar M, Sugitha TCK et al. 2018. Actinobacteria from rhizosphere: molecular diversity, distributions, and potential biotechnological applications. In: Singh BP, Gupta V, Passri AK (eds.) New and Future Developments in Microbial Biotechnology and Bioengineering. Elsevier, Amsterdam. DOI: 10.1016/B978-0-444-63994-3.00002-3. 